
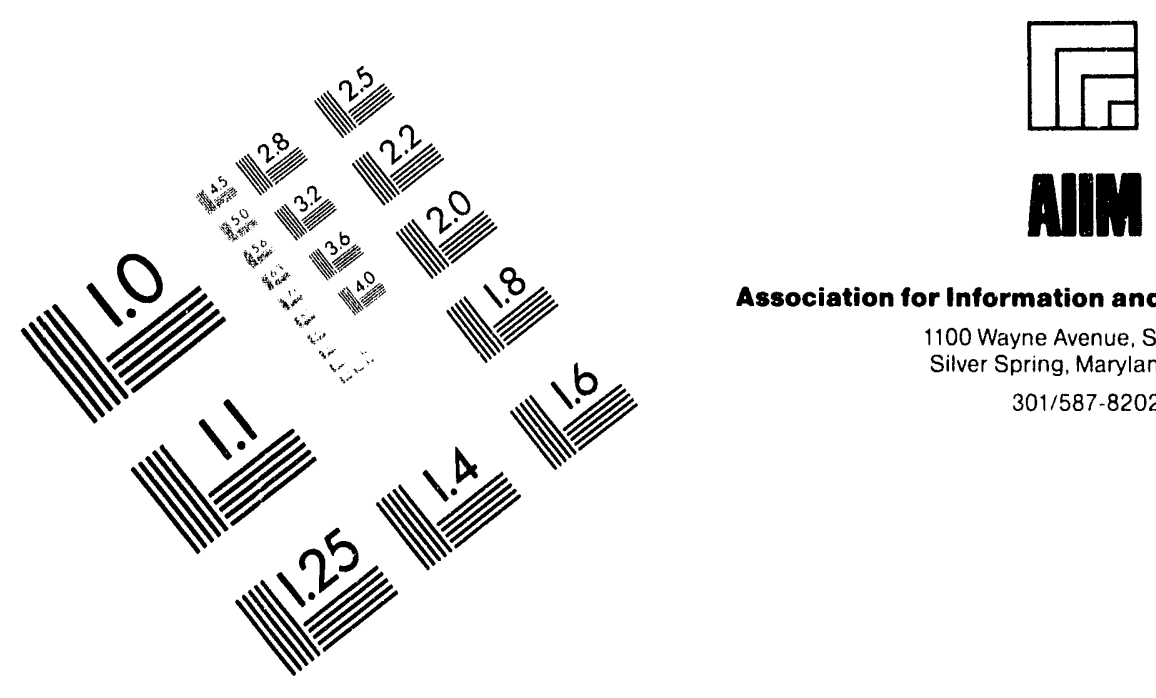

Association for Information and Image Management

1100 Wayne Avenue, Suite 1100

Silver Spring, Maryland 20910

301/587-8202

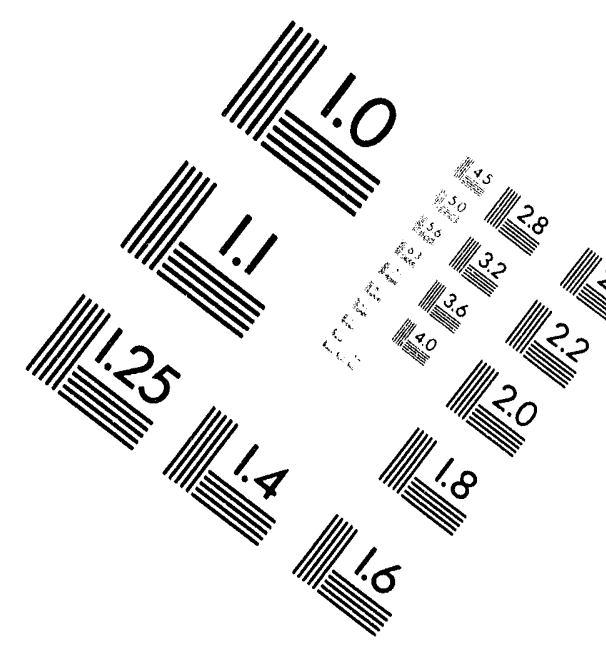

Centimeter

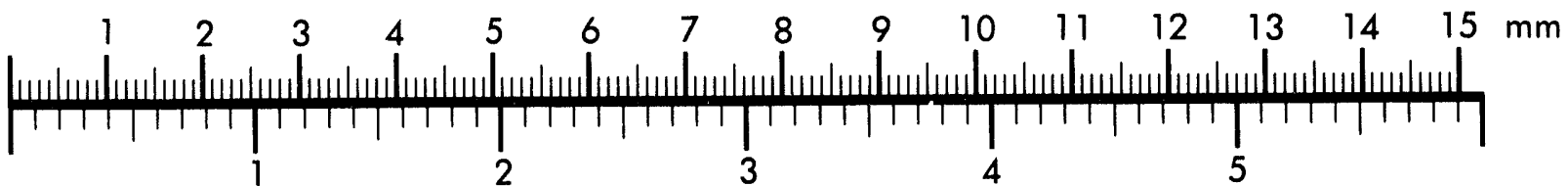

Inches
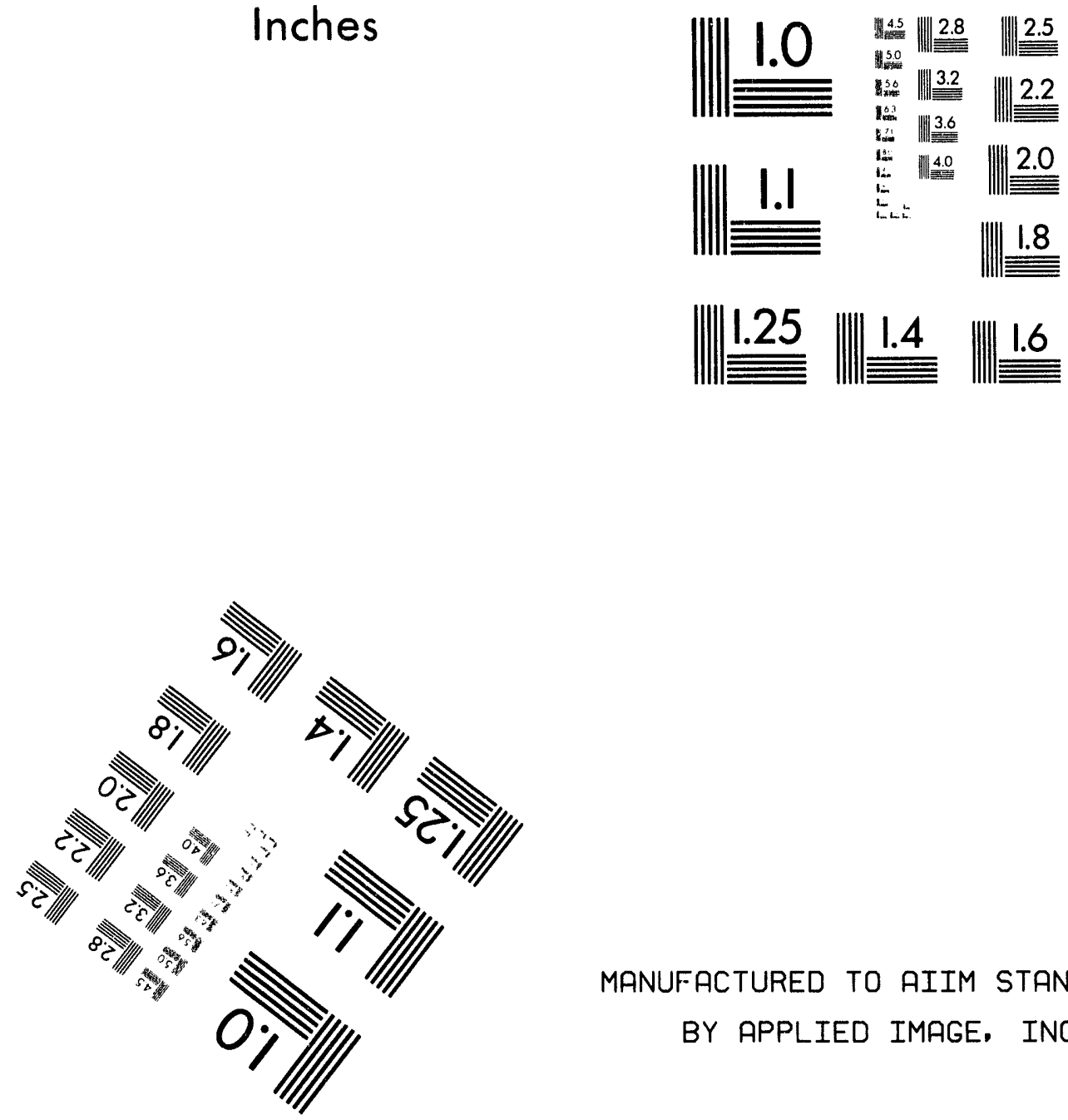

MANUFACTURED TO AIIM STANDARDS

BY APPLIED IMAGE, INC.

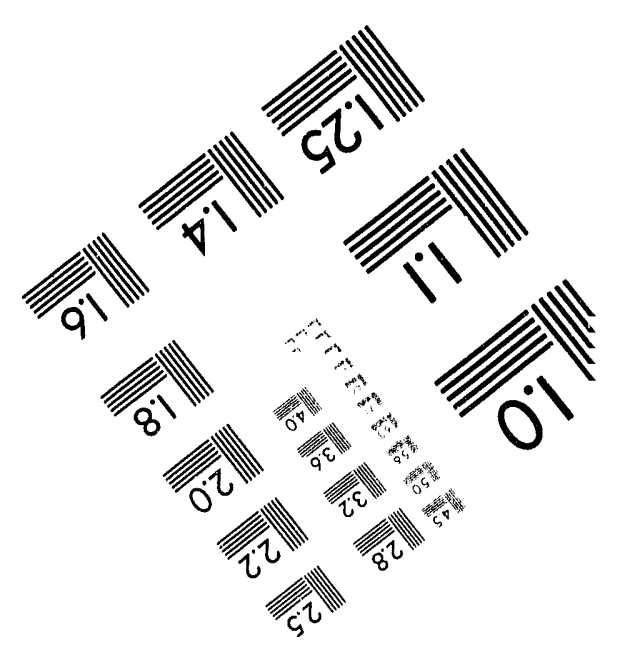



$10 / 118.94950$

SANDIA REPORT

SAND94-0766 • UC-706

Unlimited Release

Printed May 1994

\title{
A More Exact Analysis of Sandia Laser Tracker Data
}

\author{
G. S. Phipps
}

Propared by

Sandia National Laboratorios

Albuquerque, Now Moxico 87185 and Llvermore, Cellfornis 94550

for the United States Department of Enorgy

under Contrect DE-ACO4-94AL85000

Approved for public release; diatribution is unlimited.

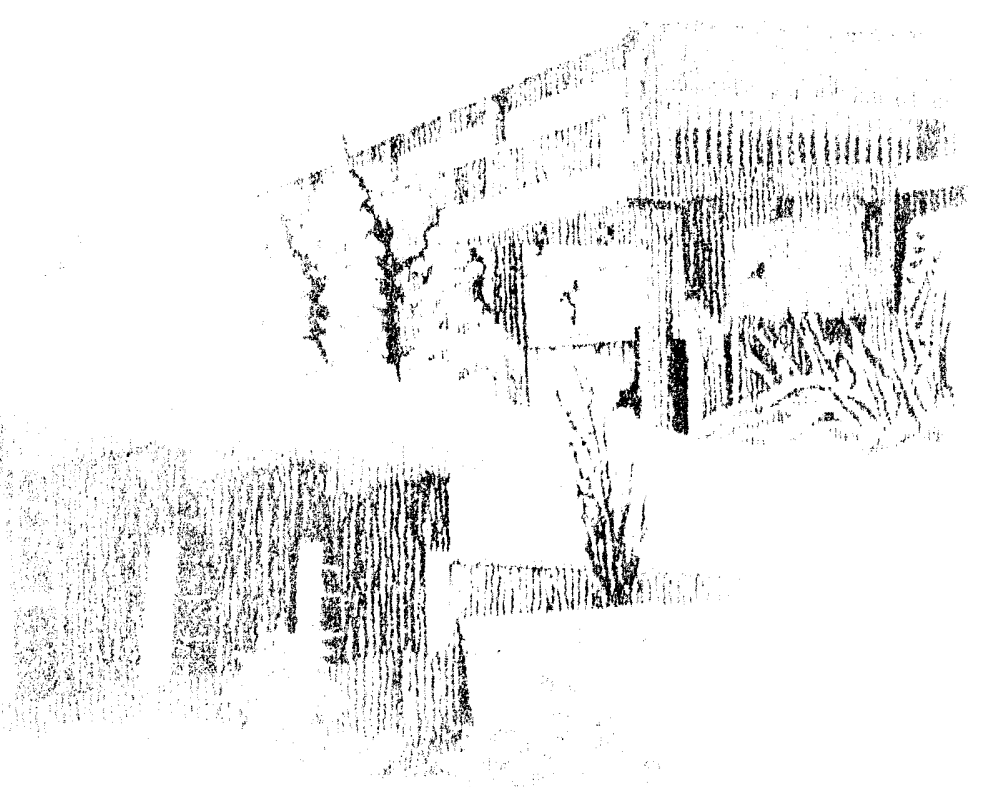


Issued by Sandia National Laboratories, operated for the United States Department of Energy by Sandia Corporation.

NOTICE: This report was prepared as an account of work sponsored by an agency of the United States Government. Neither the United States Government nor any agency thereof, nor any of their employees, nor any of their contractors, subcontractors, or their employees, makes any warranty, express or implied, or assumes any legal liability or responsibility for the accuracy, completeness, or usefulness of any information, apparatus, product, or process disclosed, or represents that its use would not infringe privately owned rights. Reference herein to any specific commercial product, process, or service by trade name, trademark, manufacturer, or otherwise, does not necessarily constitute or imply its endorsement, recommendation, or favoring by the United States Government, any agency thereof or any of their contractors or subcontractors. The views and opinions expressed herein do not necessarily state or reflect those of the United States Government, any agency thereof or any of their contractors.

Printed in the United States of America. This report has been reproduced directly from the best available copy.

Available to DOE and DOE contractors from

Office of Scientific and Technical Information

PO Box 62

Oak Ridge, TN 37831

Prices available from (615) 576-8401, FTS 626-8401

Available to the public from

National Technical Information Service

US Department of Commerce

5285 Port Royal Rd

Springfield, VA 22161

NTIS price codes

Printed copy: A03

Microfiche copy: A01 
SAND 94-0766

Unlimited Release

Printed May 1994

Distribution

Category UC-706

\title{
A More Exact Analysis of Sandia Laser Tracker Data
}

\author{
G. S. Phipps
}

Optics \& Exploratory Technologies, Department 9225

Sandia National Laboratories

Albuquerque, NM 87185-0980

\begin{abstract}
The simplified optical analysis presented in SAND 83-1123 was the basis upon which the Laser Tracker (LT) II and III data reduction routines were originally developed. Most of the assumptions used in that derivation have been eliminated in this work in an attempt to produce a more accurate data reduction. Detailed theory and vector analysis behind the data reduction and error decoupling algorithms used in the LT systems are described. Errors and corrections to the original document uncovered in over ten years of use are also noted and corrected.
\end{abstract}




\section{Acknowledgments}

The author would like to acknowledge the assistance of previous laser tracker development team members Dan Wahl (currently of Department 5912, Analysis Department II) and Pat Mahoney (currently of Department 9612, Advanced Transporter Development) who helped update and implement these algorithms in the Laser Tracker Systems. 


\section{Contents}

Introduction ......................................................... 5

Detailed Analysis of the System ................................... 6

Comparison of Results ........................................... 12

Conclusions .......................................................... 13

Appendix (Errata for SAND83-1123) .......................... 15 
(This Page Intentionally Left Blank) 


\section{Introduction}

The Sandia Laser Tracker (LT) systems illuminate a cooperative target with a diverged Argon-ion laser beam and track the resulting bright target using a servo-controlled turning mirror. Raw data is digitally recorded in real time and analyzed later when more time is available. The recorded data consists of azimuth and elevation of the tracking mirror, tracking error signals, and range to the target. If the target is tracked perfectly, the error signals will always be zero. The data reduction for this simplified, zero-error condition can be accomplished with very few lines of code. To date, all data reduction for LTI has been done using this zero-error assumption. The more general data reduction problem using the tracking error signals is a much more involved calculation and is referred to as 'using the error foldback routine'. An error foldback algorithm for use with LTII and LTIII was described in the earlier report SAND83-1123. The 'original document' mentioned below is this earlier SAND report .

The possible need for an improved LTII/III error foldback routine was investigated in the summer of 1993 during the Anti-Helicopter Mine (AHM) test series conducted at the Coyote Test Field. That test needed to determine the position of a helicopter in flight as it moved over the test range. Accuracies of a few inches were desired over tracking ranges of several thousand feet. Discrepancies uncovered in reduced data indicated a possible need for a more thorough analysis of the data reduction problem.

Without error foldback enabled the position data from reduced LT data records exhibit a degree of notchiness caused by the discrete encoder bit size. (In LTII and LTIII each encoder bit is $24 \mu$ radians.) This notchiness can be particularly noticeable at the beginning of a rocket-assisted pull-down test where zero velocity and moderately high vertical accelerations are combined to cause large error signals. The error caused by the lagging gimbal position is translated into non-trivial position errors unless an error foldback routine is used.

The earlier versions of error foldback described by SAND83-1123 produce smooth position plots when applied to such a pull-down test and appeared to be working properly. The more thorough analysis presented here, however, indicates that although the original error-foldback position data was improved, its accuracy could be made even better. The following detailed analysis applies only to LTII and LTIII. The optical system of LTI is much different, and the equations presented here do not apply. A similar routine could be developed for that system using similar vector analysis. Such an analysis was not undertaken since during the summer of $1993 \mathrm{LTl}$ was being mothballed and such an effort seemed futile.

The basic analysis of SAND83-1123, Optical Analysis of a Gimballed Mirror System, was based upon sound vector analysis. Assumptions used in that analysis were:

1. The effective pivot point of the gimballed beryllium mirror $(\mathrm{Be})$ is located on its front surface at the center of its 18 " diameter. The imaging light bundle used by the 8 " Celestron telescope (C8) was assumed to be centered on this rotational 
pivot point. In reality, the imaging bundle is offset $40-50 \mathrm{~mm}$ to the left of the Be pivot.

2. The ranging laser beam was assumed to be collinear with the imaging bundle of the C8. They are actually offset $75-100 \mathrm{~mm}$ to the right of the mirror pivot point, opposite the direction of the $\mathrm{C} 8$ offset. As the mirror rotates, the laser galvo-to$\mathrm{Be}$ distance increases while the $\mathrm{C} 8$-to-Be distance decreases, or vice versa depending upon which direction the mirror moves.

3. The ranging distance was assumed to be the same as the imaging distance. This is inexact, not only because of 1) and 2) above but also because the ranging galvos are further from the Be mirror than is the C8 telescope.

Since the tracking ranges being considered are hundreds or thousands of meters, these three points were initially deemed to be minor and were ignored. One of the improvements in the LTII (and III) software was the ability to use tracking error signals in addition to mirror encoder and range data to calculate a more accurate target trajectory. The routines that perform this 'error foldback' calculate range in multiples of the C8-to-Be distance, a distance of roughly $1.5 \mathrm{~m}$. Since all coordinate calculations utilize this distance, a few tens of millimeters change in the $\mathrm{C} 8$ relative to the gimballed mirror caused by the above factors seems potentially much more important. A new analysis is presented here that does not rely upon the above simplifications.

SAND 83-1123 addressed the solution of three problems. The changes proposed here do not affect the solution for the first two of those problems; neither the detector error crosscoupling nor the image rotation are affected by the above assumptions. The original solutions to those problems are still valid. This update is only applicable to the solution of problem 3: accurate calculation of the target location using error foldback.

Although at first glance the numbering scheme for equations and figures used below seems strange, the notation has been selected to agree with the similar equations, symbols, and figures used in the original document. Where needed, letters have been used for equations to preserve the numbering coherence with the original document. This analysis will use the symbols and nomenclature of SAND83-1123 with additional symbols added where needed to describe the added complexity.

\section{Detailed Analysis of the System}

The geometry of the LTII/III tracker optics without the above three assumptions has been drawn here as Figure 5. This is similar to SAND83-1123, Figure 5, with the addition of the parameters relating to the offset origin and separate laser galvo paths. The Be mirror origin is a fixed point in space at the center of the 18 " diameter mirror; the mirror rotates in azimuth and elevation about this point. 


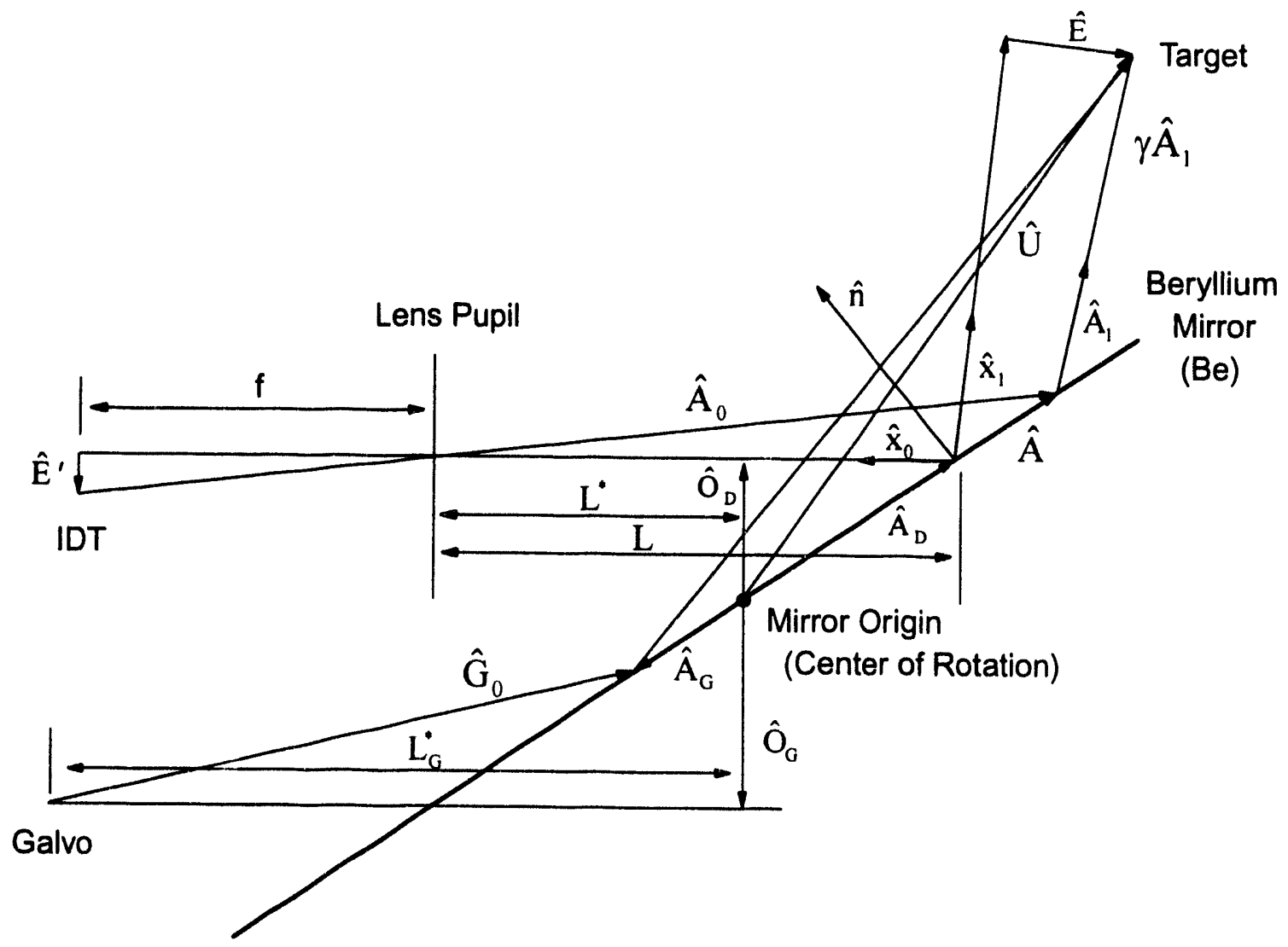

Figure 5: Geometry for a More Exact Solution of Problem 3

(for LTII and LTIII)

New terms introduced here are (terms mentioning laser beam are measured to the center of the beams):

$\hat{O}_{D}$ The offset vector from the origin to the optical axis of the C8 system, orthogonal to the $\mathrm{C} 8$ optical axis.

$\hat{\mathrm{O}}_{\mathrm{G}} \quad$ A similar offset vector from the origin to the outgoing, non-offset, galvodirected, tracking (TIDT) laser beam, orthogonal to the non-offset TIDT beam. (Not necessarily anti-parallel to $\hat{O}_{D}$ )

$\hat{A}_{D} \quad$ The vector along the surface of the Be mirror from the origin to the point of reflection of the optical axis from the $\mathrm{C} 8$.

$\hat{A}_{\mathrm{G}} \quad$ The vector along the surface of the Be mirror from the origin to the outgoing TIDT laser beam reflection.

$\mathrm{L}^{*} \quad$ The linear (fixed) distance from the C8 entrance pupil to the mirror when the Be mirror is at re-entry. (The distance to the point of reflection, $\mathrm{L}$, is now a variable.) 
$\dot{L}_{G} \quad$ The linear (fixed) distance from the Be mirror to the laser reflection point on the TIDT steering galvo closest to the $\mathrm{Be}$ mirror when the $\mathrm{Be}$ mirror is at re-entry.

$\hat{\mathrm{G}}_{0} \quad$ The vector from the laser reflection point on the TIDT steering galvo closest to the Be mirror to the TIDT laser beam reflection point on the Be mirror.

The parameters $\mathrm{L}_{\mathrm{G}}$ and $\mathrm{L}^{*}$ are determined with the Be mirror positioned orthogonal to the C8 axis. This position reflects the outgoing beams back onto themselves and is thus called 're-entry'.

The equation changes due to this new geometry begin on page 15 of the original document where equation (21) should be:

$$
\hat{U}=\hat{A}_{D}+\hat{A}+\gamma \hat{A}_{1}
$$

The math on page 17 leading up to equation (24) is valid with or without the assumptions now being removed. The original equation (24), however, contained a typographical error.

A corrected equation (24) using the new geometry and equation (25) which is unchanged from the original document are:

$$
\begin{gathered}
\hat{U}=\hat{\mathbf{x}}_{0}[L-f(1+\gamma) / \beta]-\hat{E}^{\prime}[(1+\gamma) / \beta]+\hat{n}\left[2 \gamma\left\{f\left(\hat{x}_{0} \cdot \hat{n}\right)+\left(\hat{E}^{\prime} \cdot \hat{n}\right)\right\} / \beta\right]+\hat{A}_{D} \\
\beta=\frac{f\left(\hat{x}_{0} \cdot \hat{n}\right)+\left(\hat{E}^{\prime} \cdot \hat{n}\right)}{L\left(\hat{x}_{0} \cdot \hat{n}\right)}
\end{gathered}
$$

To update to the more exact solution, the description below equation 25 in the original document should be replaced by that on the following pages:

Surveys of the LT systems are normally done to the center of the gimballed Be mirror which is also the origin in Figure 5. The exact target location relative to the fixed origin of the Be mirror is defined by $\hat{U}$ of equation (24). $\hat{\mathbf{x}}_{0}$ (the re-entry vector) and $f$ (the C8 focal ngth) are parameters of the optical bench setup and are static constants for any particular test. $\hat{n}$ (the Be mirror position) and $\hat{E}^{\prime}$ (the measured IDT error signal) are dynamic quantities that are measured and recorded throughout each test. $\beta$ is a variable defined by equation (25) and determined from the unknown $L$ and additional known quantities. $\gamma$, and $\hat{A}_{D}$ are remaining unknowns in equation (24). There are only three unknown quantities to be evaluated before $\hat{U}$ can be quantified: $L, \gamma$, and $\hat{A}_{D}$. 
The term, L, in both Equations (24) and (25) originally was a constant. Since the C8 optical axis no longer intersects the mirror origin, the distance $L$ is now a variable.

Referring to Figure 5:

$$
L \hat{x}_{0}=L^{*} \hat{x}_{0}-\hat{A}_{D}+\hat{O}_{D}
$$

Rearranging equation (a):

$$
\hat{A}_{D}=L^{*} \hat{x}_{0}-L \hat{x}_{0}+\hat{O}_{D}
$$

Combining equations (24) and (b) results in a new definition of $\hat{U}$ which has no direct reference to $\hat{A}_{D}$ or $L$ :

$\hat{U}=\hat{x}_{0}\left[L^{*}-f(1+\gamma) / \beta\right]-\hat{E}^{\prime}[(1+\gamma) / \beta]+\hat{n}\left[2 \gamma\left\{f\left(\hat{x}_{0} \cdot \hat{n}\right)+\left(\hat{E}^{\prime} \cdot \hat{n}\right)\right\} / \beta\right]+\hat{O}_{D}$

$\mathrm{L}$ is still needed to evaluate equation (25). Dotting each side of equation (a) with $\hat{n}$ :

$$
L \hat{x}_{0} \cdot \hat{n}=L^{*} \hat{x}_{0} \cdot \hat{n}-\hat{A}_{D} \cdot \hat{n}+\hat{O}_{D} \cdot \hat{n}
$$

The dot product of $\hat{\mathrm{A}}_{\mathrm{D}}$ and $\hat{\mathrm{n}}$ is zero since they are orthogonal vectors, therefore:

$$
\mathrm{L}=\mathrm{L}^{*}+\frac{\hat{\mathrm{O}}_{\mathrm{D}} \cdot \hat{\mathrm{n}}}{\hat{\mathrm{x}}_{0} \cdot \hat{\mathrm{n}}}
$$

$\gamma$ is the only remaining unknown term. The laser beam path distance from the laser galvo to the target in LTII/III before and after the Be reflection is the path:

$$
\left|\hat{\mathrm{G}}_{0}\right|+\left|-\hat{\mathrm{A}}_{\mathrm{G}}+\mathrm{L}^{*} \hat{\mathrm{x}}_{0}+\hat{\mathrm{O}}_{\mathrm{D}}+\hat{\mathrm{A}}_{0}+\gamma \hat{\mathrm{A}}_{1}\right|
$$

The return beam from the target follows the similar path:

$$
\left|-\gamma \hat{\mathrm{A}}_{1}\right|+\left|-\hat{\mathrm{A}}_{0}\right|
$$

The round-trip distance quantity measured by the ranging system was originally ascribed a definition expressed in these updated symbols as $2\left(\mathrm{R}+\mathrm{L}_{\mathrm{G}}{ }_{\mathrm{G}}\right)$, i.e. $2 \mathrm{x}$ (target range + galvo setback distance). Since $\mathrm{L}_{\mathrm{G}}$ is now a variable, this definition has less meaning. Instead let us say that the ranging system measures a quantity, D, which at reentry would 
nominally have the value $2\left(R+\mathrm{L}_{\mathrm{G}}^{*}\right)$. Combining this definition of $\mathrm{D}$ with expressions (d) and (e):

$$
D=\left|\hat{A}_{0}\right|+\left|\gamma \hat{A}_{1}\right|+\left|\hat{G}_{0}\right|+\left|-\hat{A}_{G}+L^{*} \hat{x}_{0}+\hat{O}_{D}+\hat{A}_{0}+\gamma \hat{A}_{1}\right|
$$

$\hat{A}_{0}$ can be determined by the equation immediately preceding the original equation (22):

$$
\hat{\mathrm{A}}_{0}=-\left(\hat{\mathrm{x}}_{0}+\hat{\mathrm{E}}^{\prime}\right) / \beta
$$

$\hat{A}_{1}$ is similarly evaluated using the law of reflection:

$$
\hat{A}_{1}=\hat{A}_{0}-2\left(\hat{A}_{0} \cdot \hat{n}\right) \hat{n}
$$

$\hat{\mathrm{A}}_{\mathrm{G}}, \hat{\mathrm{G}}_{0}$, and $\gamma$ are not immediately obvious. Referring to Figure 5: assume that the $\mathrm{C} 8$ optical axis and the outgoing, non-offset, galvo-directed laser beam are parallel. (This is a good assumption since the optical bench setup strives to achieve this condition.) We can write:

$$
\hat{A}_{G}-\hat{G}_{0}=\hat{O}_{G}+\dot{L}_{G}^{*} \hat{x}_{0}
$$

The following assumption will also be made:

$$
\hat{\mathrm{G}}_{0}=\mathrm{q} \hat{\mathrm{A}}_{0}
$$

In other words, the vectors from the $\mathrm{C} 8$ to the mirror and from the laser galvos to the mirror are parallel. This is not exactly true since both vectors must fall onto the same point at the target. Parallel vectors, even if reflected from a flat turning mirror, can fall onto a common point only if that point is an infinite distance away. A similar assumption is used when positioning the laser galvos to an off-axis target using the tracking error signals. Since this positioning works reliably, the error of this assumption has experimentally been proven to be small. The present purpose is to determine the linear distance from the galvos to the $\mathrm{Be}$ mirror and the small error introduced by assumption (i) will be deemed insignificant. Using (h) and (i):

$$
\hat{A}_{G}=\hat{O}_{G}+L_{G}^{*} \hat{x}_{0}+q \hat{A}_{0}
$$


The term q can be evaluated by dotting each side of equation $(j)$ with $\hat{n}$ and solving:

$$
q=\frac{\hat{O}_{G} \cdot \hat{n}+L_{G}^{*}\left(\hat{x}_{0} \cdot \hat{n}\right)}{-\left(\hat{A}_{0} \cdot \hat{n}\right)}
$$

To solve for $\gamma$, use equations (i) and (j) to rewrite equation (f):

$$
D=\left|\hat{A}_{0}\right|+\left|\gamma \hat{A}_{1}\right|+\left|q \hat{A}_{0}\right|+\left|-\hat{O}_{G}-L_{G}^{*} \hat{x}_{0}-q \hat{A}_{0}+L^{*} \hat{x}_{0}+\hat{O}_{D}+\hat{A}_{0}+\gamma \hat{A}_{1}\right|
$$

Collect terms:

$$
\mathrm{D}=\left|\hat{\mathrm{A}}_{0}\right|+\left|\gamma \hat{\mathrm{A}}_{1}\right|+\left|q \hat{\mathrm{A}}_{0}\right|+\left|\hat{\mathrm{O}}_{\mathrm{D}}-\hat{\mathrm{O}}_{\mathrm{G}}+\hat{\mathrm{x}}_{0}\left(\mathrm{~L}^{\cdot}-\dot{\mathrm{L}}_{\mathrm{G}}\right)+\hat{\mathrm{A}}_{0}(1-\mathrm{q})+\gamma \hat{\mathrm{A}}_{1}\right|
$$

To simplify notation, define a new term which contains only known quantities:

$$
\hat{\mathrm{t}}=\hat{\mathrm{O}}_{\mathrm{D}}-\hat{\mathrm{O}}_{\mathrm{G}}+\hat{\mathrm{x}}_{0}\left(\mathrm{~L}^{*}-\mathrm{L}_{\mathrm{G}}^{*}\right)+\hat{\mathrm{A}}_{0}(1-\mathrm{q})
$$

Rewrite equation (l) using the definition of equation (m) :

or

$$
D=\left|\hat{A}_{0}\right|+\left|\gamma \hat{A}_{1}\right|+\left|q \hat{A}_{0}\right|+\left|\hat{t}+\gamma \hat{A}_{1}\right|
$$

$$
D-(q+1)\left|\hat{A}_{0}\right|-\gamma\left|\hat{A}_{1}\right|=\left|\hat{t}+\gamma \hat{A}_{1}\right|
$$

Realize that:

$$
\left|\hat{\mathrm{t}}+\gamma \hat{\mathrm{A}}_{1}\right|^{2}=|\hat{\mathrm{t}}|^{2}+\gamma^{2}\left|\hat{\mathrm{A}}_{1}\right|^{2}+2 \gamma\left(\hat{\mathrm{t}} \cdot \hat{\mathrm{A}}_{1}\right)
$$

Since $(n)$ is a scalar equation each side can be squared and rewritten with the aid of $(p)$ :

$$
\left[D-(q+1)\left|\hat{A}_{0}\right|-\gamma\left|\hat{A}_{1}\right|\right]^{2}=|\hat{\mathrm{t}}|^{2}+\gamma^{2}\left|\hat{\mathrm{A}}_{1}\right|^{2}+2 \gamma\left(\hat{\mathrm{t}} \cdot \hat{\mathrm{A}}_{1}\right)
$$

Defining the constant $\mathrm{c}$ as:

$$
c=D-(q+1)\left|\hat{A}_{0}\right|
$$

Use (r) to expand the left side of (q) and collect terms:

$$
c^{2}+\gamma^{2}\left|\hat{\mathrm{A}}_{1}\right|^{2}-2 \gamma \mathrm{c}\left|\hat{\mathrm{A}}_{1}\right|=|\hat{\mathrm{t}}|^{2}+\gamma^{2}\left|\hat{\mathrm{A}}_{1}\right|^{2}+2 \gamma\left(\hat{\mathrm{t}} \cdot \hat{\mathrm{A}}_{1}\right)
$$


Rearranging:

$$
2 \gamma\left\{c\left|\hat{A}_{1}\right|+\left(\hat{\mathrm{t}} \cdot \hat{\mathrm{A}}_{1}\right)\right\}=\mathrm{c}^{2}-|\hat{\mathrm{t}}|^{2}
$$

Producing an equation for the final unknown of equation (24a) with all known terms:

$$
\gamma=\frac{c^{2}-|\hat{t}|^{2}}{2\left[c\left|\hat{A}_{1}\right|+\left(\hat{t} \cdot \hat{A}_{1}\right)\right]}
$$

The actual range to the tracked target will be the absolute value of the $\hat{U}$ vector of equation (24a).

\section{Comparison of Results}

The data presented in the tables below indicates the difference in calculated helicopter position from two locations for a particular test during the AHM series using different data reduction routines. The original survey for the tracker was done so that the reduceddata coordinates for the GPS origin would be approximately $(0,0,0)$. The original error foldback produces essentially this $(0,0,0)$ location since it was used to calculate the coordinate transformations that convert tracker coordinates into test coordinates. Any deviation from $(0,0,0)$ is an indication of either original survey errors, movement of the tracker after the initial survey, or errors caused by the discreet data used in the setup routines.

\begin{tabular}{|c|c|c|c|c|c|}
\hline & No Foldback & $\begin{array}{c}\text { Previous } \\
\text { Foldback }\end{array}$ & $\begin{array}{c}\text { Change wrt } \\
\text { No Foldback }\end{array}$ & $\begin{array}{c}\text { Foldback using } \\
\text { Equation (24a) }\end{array}$ & $\begin{array}{c}\text { Change wrt } \\
\text { No Foldback }\end{array}$ \\
\hline $\mathrm{X}$ & 0.1797 & 0.1797 & - & 0.9756 & +0.7959 \\
\hline $\mathrm{Y}$ & 0.05396 & 0.05396 & - & 0.1681 & +0.1141 \\
\hline $\mathrm{Z}$ & 0.002172 & 0.002034 & -0.000138 & -0.03194 & -0.0341 \\
\hline Range & 0.1876 & 0.1876 & -0.000002 & 0.9905 & +0.8029 \\
\hline
\end{tabular}

Table 1: Calculated Position for GPS Origin (in feet)

The No Foldback origin position in Table 1 is nearly $(0,0,0)$ as would be expected for a stationary target located there. The previously used foldback routine calculated positions which were identical to the no foldback condition since the tracking errors were essentially zero with a stationary target. The present, more correct error foldback changes the calculated positions by 9.6 inches in $\mathrm{X}$ and 1.4 inches in $\mathrm{Y}$. In this example 
calculated Z-axis position is little affected by the error foldback. This is not expected to be the case in general. Because of the severe axis cross-coupling caused by the inclined optical axis inside the tracker, the $Z$ axis differences are expected to be similar in magnitude to those for $\mathrm{X}$ and $\mathrm{Y}$ for the general tracking case.

\begin{tabular}{|c|c|c|c|c|c|}
\hline & No Foldback & $\begin{array}{c}\text { Previous } \\
\text { Foldback }\end{array}$ & $\begin{array}{c}\text { Change wrt } \\
\text { No Foldback }\end{array}$ & $\begin{array}{c}\text { Foldback using } \\
\text { Equation (24a) }\end{array}$ & $\begin{array}{c}\text { Change wrt } \\
\text { No Foldback }\end{array}$ \\
\hline $\mathrm{X}$ & 0.000488 & 0.000488 & - & 0.41748 & +0.417 \\
\hline $\mathrm{Y}$ & -7620.805 & -7620.804 & +0.001 & -7621.492 & -0.6870 \\
\hline $\mathrm{Z}$ & 8.6974 & 8.6975 & +0.0001 & 8.7198 & +0.0224 \\
\hline Range & 7620.810 & 7620.809 & -0.001 & 7621.497 & +0.687 \\
\hline
\end{tabular}

Table 2: Calculated Position for South Flight Line Marker (in feet)

Table 2 is similar data for the south flight line marker. Again the previous foldback made no appreciable difference and the present algorithms shift the positions by several inches. In both of these cases there is very little tracking error since stationary targets were being tracked at the respective locations. Other geometries which place the target at different angles and ranges with respect to the gimbal may cause a much greater or lesser coordinate shift than indicated by these examples. In a dynamic tracking situation the track error becomes appreciable and the calculated coordinate differences may be even greater.

\section{Conclusion}

A new, more accurate algorithm for error-foldback has been developed for the Sandia Laser Tracker Systems II and III. The improvement in accuracy depends greatly upon the geometry and the tracking errors encountered during a particular test. The calculated position differences can easily be on the order of a foot or more for typical stationary tracking applications. Even greater differences could be encountered for highly dynamic tests at arbitrary angles to the tracker. The newer algorithms should always be used when accurate position data is required. 
(This Page Intentionally Left Blank)

$-14-$ 
Appendix

Errata for SAND83-1123

Page \#

(unrelated to updated equation changes)

9 The line above equation (1) should read:

' plane and normal to the plane of the mirror (Figure 2b): '

Last sentence on the page:

Replace $\hat{E}$ with $\hat{E}^{\prime}$

12 Equation (11), the scalar and vector symbols are in error:

Replace $\hat{L} x_{0}$ with $\mathbf{L} \hat{x}_{0}$

15 In the paragraph following Equation (20), the last line should read:

'... parallel to the $\mathrm{z}$ axis.'

17 Since nearly this entire page has been superseded by the more exact analysis of this report, this page could almost be ignored. For comparison purposes, however:

The last '-' sign of Equation (24) should be a ' + '.

The derivation of Equation (25) should begin:

$$
\hat{\mathrm{A}} \cdot \hat{\mathrm{n}}=0=\ldots
$$

21 Second paragraph. Delete the last two sentences and insert the following:

These vectors change magnitude and direction as $\mathrm{A}$ and $\mathrm{E}$ change.

Beginning with the fourth paragraph the page should read:

The tracking detector image plane of Figure 4 is redrawn as Figure 10. The detector measures orthogonal $\left(x^{\prime}, y^{\prime}\right)$ error components of $\hat{E}^{\prime}$. At range, $R$, the space error vector, $\hat{E}=R \hat{S}_{A}$, when imaged by the detector optics, will produce $\hat{E}^{\prime}$ with magnitude Maga in the direction Dira. Likewise, at range $\mathrm{R}$, an $\hat{E}=R \hat{S}_{\mathrm{E}}$ will map to a magnitude Mage in the direction Dire. To produce true $\mathrm{A}$ and $\mathrm{E}$ error signals to drive the mirror servos, coordinate transformations are needed.

From Figure 10:

$$
\mathbf{x}^{\prime}=\mathrm{A} \mathrm{Maga} * \cos (\text { Dira })+\mathrm{EMage}^{*} \cos (\text { Dire })
$$




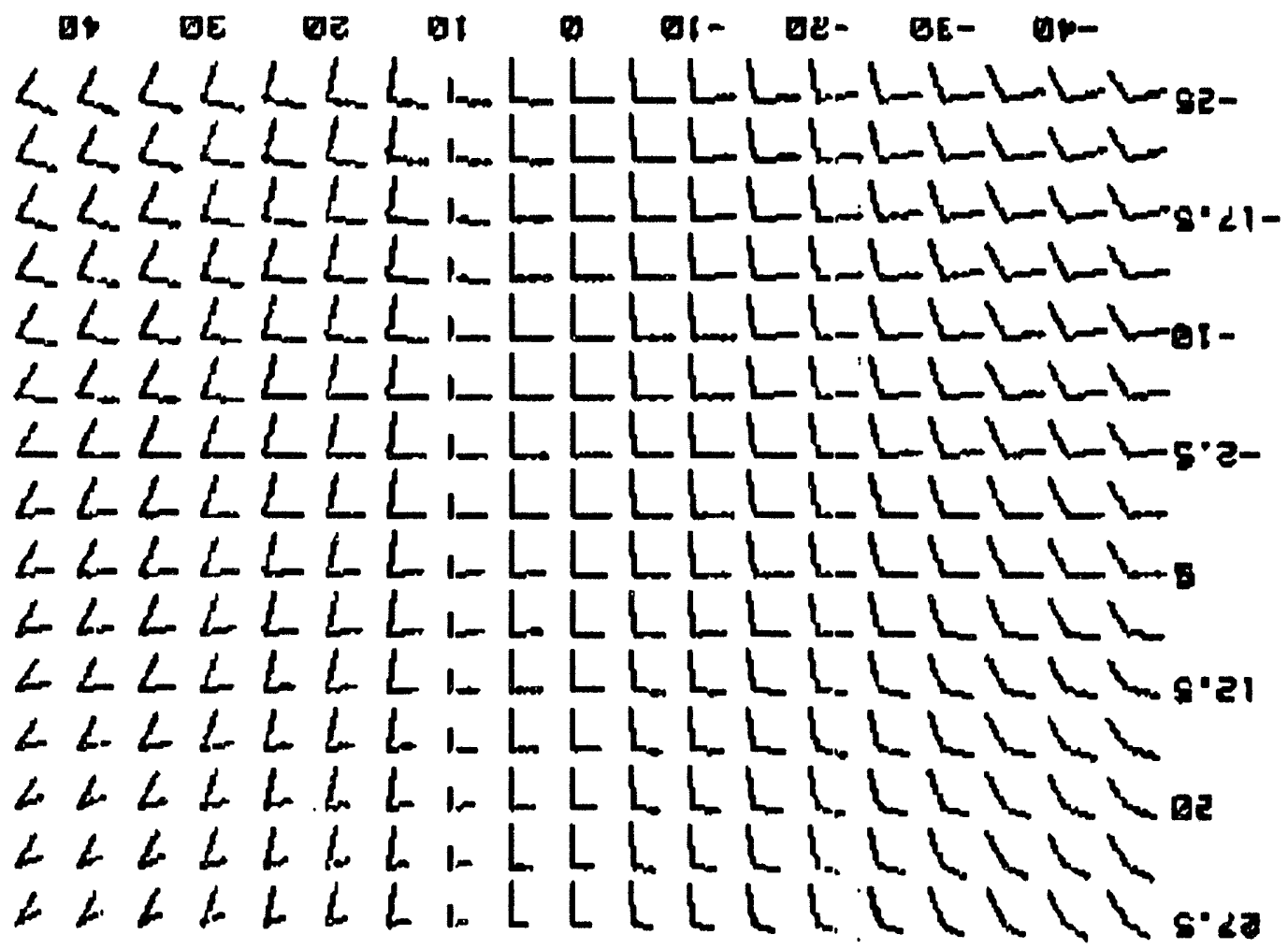

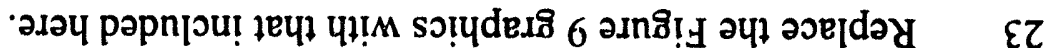
\#28ह

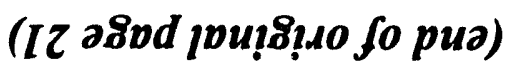

of asnpad suo!̣enba

8ิน!!

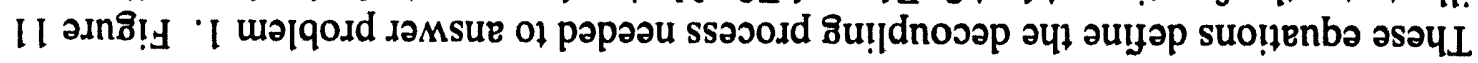

$$
\begin{aligned}
& 2 \exists, \kappa+19, x=
\end{aligned}
$$

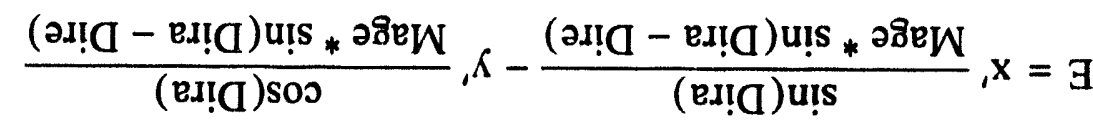

$\tau \forall, K+I \forall, x=$

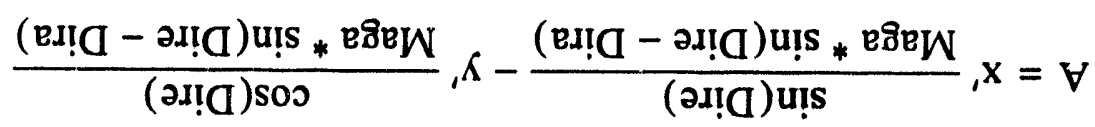

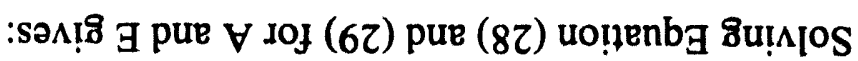

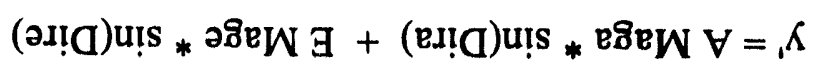




\section{Page \#}

24 Re-label the vector at angle Dira as Maga and the other as Mage. The caption should be replaced with:

Maga is the length of the vector $\hat{E}^{\prime}$ produced by imaging a space error vector, $R \hat{S}_{A}$, positioned at the head of $\mathrm{RS}_{1}$ indicating a unit change of mirror normal angle, $\mathrm{A}$ (See Figure 4). Likewise, Mage is the length of $R \hat{S}_{E}$ imaged at range $R$.

25 Replace the Figure 11 graphics with those included here.
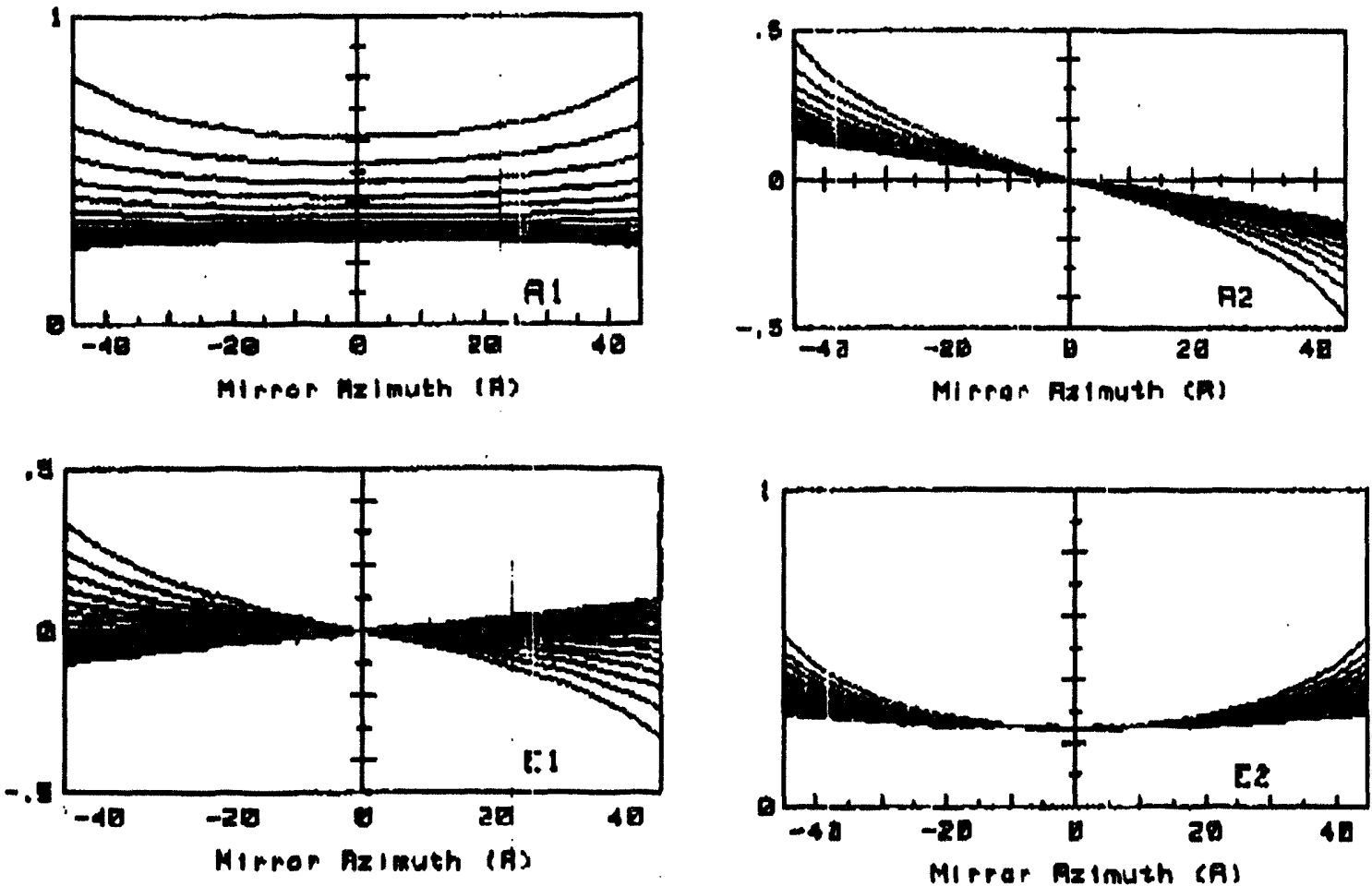
Page \#

26 The entire page should be replaced with the following:

$$
\begin{aligned}
& A=\frac{x^{\prime}}{\text { Maga }} \\
& E=\frac{y^{\prime}}{\text { Mage }}
\end{aligned}
$$

which is the uncoupled condition referred to earlier. The term Mage $\approx 2 \mathrm{f}$ in this region indicates that the angular deflection of the beam in elevation is nearly twice the movement of the mirror. The Maga term is somewhat more $[\approx 2 \mathrm{f} / \cos (35)]$ near $A=0$, and varies with both $A$ and $E$ of the mirror. As the elevation of $\hat{s}_{1}$ increases, a smaller angular displacement represents a unit change of $A$. In the limit at $E=55$ the outgoing beams are parallel to the $\mathrm{Be}$ mirror and $\mathrm{A}$ has no effect on $\hat{\mathrm{s}}_{1}$, i.e. $\mathrm{Maga}=0$.

If the $\left(x^{\prime}, y^{\prime}\right)$ coordinate system of Figure 10 could be rotated clockwise either electrically or mechanically by the function (90-Dire), the E error axis would always fall on the $y^{\prime}$ axis. This would be equivalent to replacing Dira with (90-Dire+Dira) and Dire with (90) in Equations (28) and (29). The resulting forms would be:

$$
\begin{aligned}
& \mathrm{x}^{\prime \prime}=\mathrm{A} \text { Maga } * \sin (\text { Dire }- \text { Dira }) \\
& \mathrm{y}^{\prime \prime}=\mathrm{A} \text { Maga } * \cos (\text { Dire }- \text { Dira })+\mathrm{E} * \text { Mage }
\end{aligned}
$$

Solving these yields:

$$
\begin{aligned}
& A=\frac{x^{\prime \prime}}{\text { Maga }^{*} \sin (\text { Dire }- \text { Dira })} \\
& E=\frac{-x^{\prime \prime} * \cos (\text { Dire }- \text { Dira })}{\text { Mage } * \sin (\text { Dire - Dira })}+\frac{y^{\prime \prime}}{\text { Mage }}
\end{aligned}
$$

This reduces from four to three the number of coefficient terms in the decoupling of $\mathrm{A}$ and $\mathrm{E}$. It also introduces the complexity of physically rotating the $\left(x^{\prime}, y^{\prime}\right)$ coordinate frame of the detector. This rotation might negate the simplification in the decoupling functions.

\section{Conclusions}

Solving the original problems of error decoupling, image rotation, and trajectory calculations makes it possible to implement solutions either exactly or with approximations of varying crudeness. Any approximation can be judged as to its suitability for use in LTII by comparing it with the exact solution.

(End of original page 26) 
Page \#

29-42 There are minor corrections to the computer code listing found here to reflect the above changes. These listings are for an HP9845 desktop computer which is a rarity in 1994. Given the low probability that anyone would attempt to execute this code, no corrections are given here. With the theory presented, a proper coding into any computer language should be possible. 


\section{DISTRIBUTION:}

$\begin{array}{crlr}1 & \text { MS 0503 } & \text { G. M. Boyd } & \text { Dept } 2335 \\ 1 & 0507 & \text { R. A. David } & 2700 \\ 1 & 0615 & \text { R. A. Hill } & 2704 \\ 1 & 0555 & \text { K. C. Bauhs } & 2742 \\ 1 & 1135 & \text { M. S. Garrett } & 2761 \\ 1 & 1135 & \text { D. L. Shamblin } & 2761 \\ 1 & 1135 & \text { D. L. Patrick } & 2761 \\ 1 & 0765 & \text { M. J. Hicks } & 5861 \\ 1 & 0572 & \text { D. E. Wahl } & 5912 \\ 1 & 0717 & \text { W. M. McMurtry } & 6642 \\ 1 & 1303 & \text { E. D. Thalhammer } & 7573 \\ 1 & 0970 & \text { T. A. Sellers } & 9200 \\ 1 & 0980 & \text { C. A. Boye } & 9225 \\ 5 & 0980 & \text { G. S.Phipps } & 9225 \\ 1 & 0790 & \text { P. A. Mahoney } & 9612 \\ 1 & 9018 & \text { Central Technical Files } & 8523-2 \\ 5 & 0899 & \text { Technical Library } & 7141 \\ 1 & 0619 & \text { Technical Publications } & 7151 \\ 10 & 0100 & \text { Document Processing } & 7613-2 \\ & & \text { For DOE/OSTI } & \end{array}$



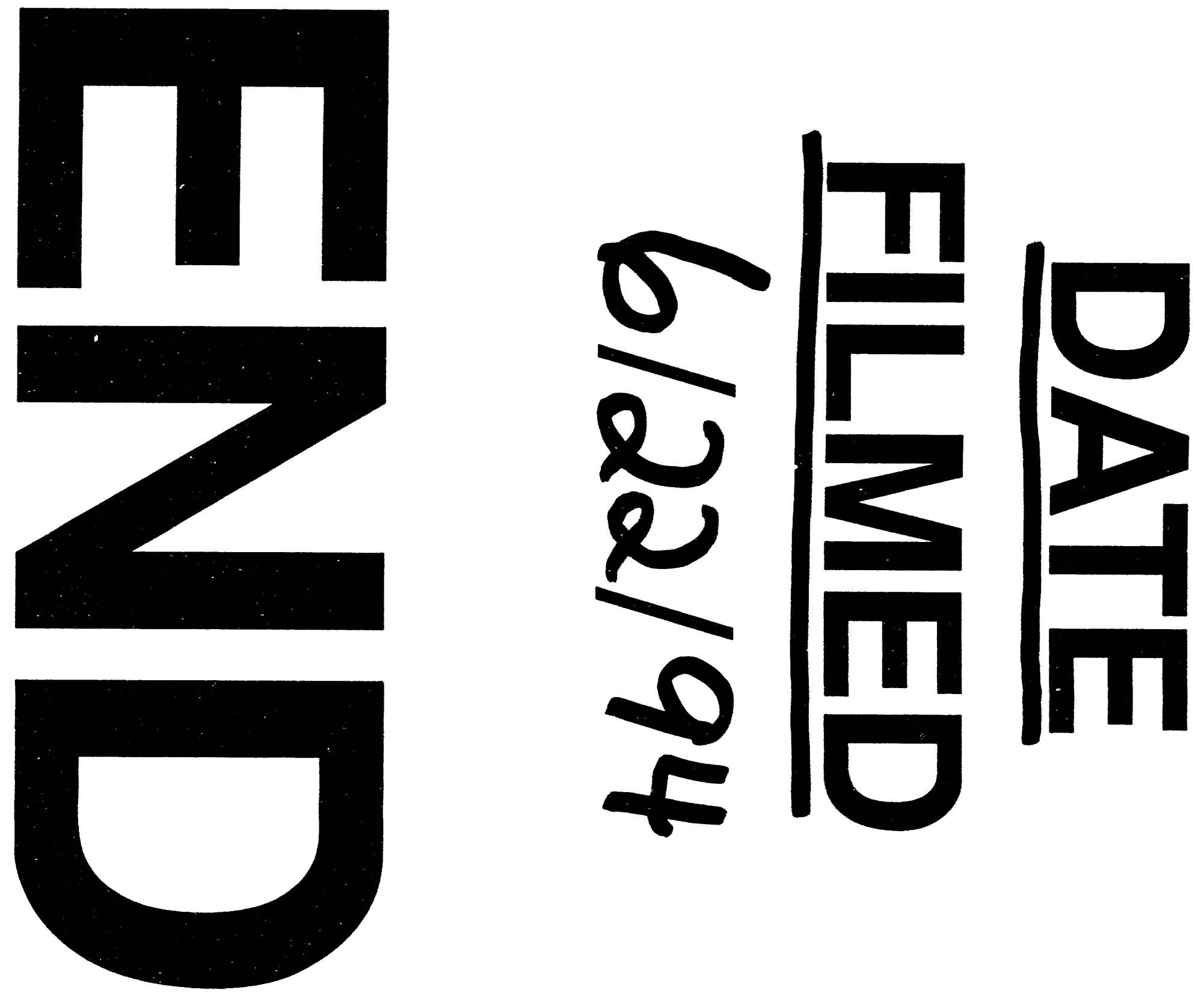
